\title{
O NEOLIBERALISMO PEDAGÓGICO COMO PRODUTO DO SUJEITO EMPRESARIAL: ameaças à democracia educacional
}

\author{
Altair Alberto Fávero \\ Universidade de Passo Fundo - UPF \\ Carina Tonieto \\ Instituto Federal de Educação, Ciência e Tecnologia do Rio Grande do Sul - IFRS \\ Evandro Consaltér \\ Universidade de Passo Fundo - UPF
}

\begin{abstract}
Resumo
Pretendemos, neste ensaio, por meio de um estudo qualitativo, caracterizado como bibliográfico, ancorado no método dedutivo-analítico, discutir algumas ligações entre o "sujeito empresarial" ou “neossujeito”, abordado por Dardot e Laval (2016), e o processo de mercantilização da educação, orientados pela pergunta: quais são os impactos dessa nova ordem social sobre a educação básica (ou escola)? Entendemos que essa ligação materializa-se, sobretudo, pelo que Tello (2013) identifica como neoliberalismo pedagógico, um movimento global que tem renunciado imprudentemente nas matrizes curriculares competências que são indispensáveis à sobrevivência das sociedades democráticas, como as disciplinas relacionadas às artes e humanidades e acentuado um processo de privatização da educação. Dessa forma, para melhor, organizamos o texto em três partes: i) exploramos a origem e a caracterização do neossujeito ou sujeito empresarial a partir de Dardot e Laval (2016); ii) da compreensão e contextualização do sujeito empresarial, analisamos a sua ligação com o conceito de neoliberalismo pedagógico abordado por Tello (2013); iii) por fim, nos deteremos aos impactos que essa nova ordem social acarreta sobre o sistema educacional, materializados principalmente pela privatização da educação e suas implicações à democracia educacional.
\end{abstract}

Palavras-chave: Sujeito empresarial. Neoliberalismo pedagógico. Democracia educacional.

\begin{abstract}
We intend, in this essay, through a qualitative study, characterized as bibliographic, anchored in the deductive-analytical method, to discuss some links between the "business subject" or "neosubject", approached by Dardot and Laval (2016), and the process of commodification of education, guided by the question: what are the impacts of this new social order on basic education (or school)? We understand that this connection materializes, above all, by what Tello (2013) identifies as pedagogical neoliberalism, a global movement that has recklessly renounced in the curricular matrices competences that are indispensable to the survival of democratic societies, such as disciplines related to the arts and humanities and accentuated a process of privatization of education. Thus, for the best, we organize the text in three parts: i) we explore the origin and characterization of the "neosubject" or "business subject" from Dardot and Laval (2016); ii) the understanding and contextualization of the business subject, we analyze its connection with the concept of pedagogical neoliberalism approached by Tello (2013); iii) Finally, we will dwell on the impacts that this new social order entails on the educational system, materialized mainly by the privatization of education and its implications for educational democracy.
\end{abstract}

Keywords: Business subject. Pedagogical neoliberalism. Educational Democracy. 


\section{Introdução}

Em seu livro Internacionalização das políticas educacionais: transformações e desafios, o professor e pesquisador Abdeljalil Akkari (2011) afirma que não é por acaso que a escola parece estar, há alguns anos, na mira do setor privado e, desse ponto de vista, constitui-se no grande mercado do século XXI. De acordo com Akkari (2011), os bilhões de dólares gastos anualmente pelos estados e pelas famílias na educação instigam esse interesse. Trata-se de um mercado garantido e inesgotável. A mesma constatação é feita por Laval (2004), cintado o ex-ministro da educação da França, Claude Allègre, o qual afirmava já há décadas que a educação era "o grande mercado do próximo século", por ser uma atividade cujo custo e rendimento é assimilável a uma mercadoria. Esse novo mercado tem atraído o capital externo e influenciado na elaboração de políticas educacionais que favorecem a perpetração do setor privado sobre o público e, assim, tratando a educação como uma mercadoria, um bem de consumo.

Essa concepção mercadológica de educação é minada pela supervalorização de resultados imediatos e em curto prazo, o que deriva uma acentuada projeção de modelos de formação docente "facilitada", de venda de pacotes formativos, de trabalhadores que atuam como freelance e consultores em educação. Esses profissionais orientam sua prática no intuito de potencializar resultados e qualificar indicadores externos, que funcionariam, em tese, como indicativos de qualidade diante dos processos de internacionalização da educação e de uma busca rápida por resultados. Além disso, essa concepção de educação favorece a perpetração do setor privado sobre o público, a emergência dos "empresários da educação", numa ótica de privatização do setor e mudam radicalmente a essência da escola e da identidade docente.

Diante deste contexto, acreditamos que o "sujeito empresarial" descrito por Dardot e Laval (2016), um sujeito que tem total envolvimento consigo, possui muitas relações com este novo cenário. Este sujeito é o responsável pelo que Teodoro (2011) chama de "nova ordem social", um novo paradigma que, justamente, valoriza a busca rápida por resultados, indicadores, dados e repulsa aos ideais de longo prazo. Assim, pretendemos enfrentar ao longo dessa investigação o seguinte problema: quais são os impactos dessa nova ordem social sobre a educação básica? Entendemos que ela é afetada principalmente pelo que Tello (2013) chama de neoliberalismo pedagógico, um processo que, além de favorecer a perpetração do setor privado sobre o público, pode acarretar a perda de sentido e de identidade da escola e da democracia educacional.

Dessa forma, tentaremos mostrar por meio deste estudo como o neoliberalismo pedagógico pode acarretar esses prejuízos à educação, desenvolver mecanismos de seleção e exclusão e, além disso, colocar em risco a democracia e o bem estar social das próximas gerações. Para alcançar o objetivo proposto, desenvolvemos um estudo qualitativo, caracterizado como bibliográfico e ancorado no método dedutivo-analítico. A pesquisa assim delineada permite reconstruir o conhecimento científico historicamente acumulado sobre um 
determinado problema e oferece o aporte necessário para que se possa, a partir dessa sistematização, elaborar novas hipóteses/problemas e interpretações. Além disso, pode se constituir num referencial analítico para outras pesquisas. Por sua vez, o método dedutivoanalítico permite o estudo aprofundado de hipóteses e explicações disponíveis visando a explicação de um determinado fenômeno.

Para melhor desenvolvimento do estudo, estruturamos o texto em três partes: i) inicialmente exploramos a origem e a caracterização do neossujeito ou sujeito empresarial abordado por Dardot e Laval (2016); ii) a partir dessa compreensão e contextualização do sujeito empresarial, analisamos a sua ligação com o conceito de neoliberalismo pedagógico explorado por Tello (2013); iii) e, por fim, nos deteremos nos impactos que essa nova ordem social acarreta sobre o sistema educacional, principalmente sob o efeito da privatização da educação, e, consequentemente, sobre o bem estar das sociedades democráticas.

\section{O neossujeito ou sujeito empresarial na educação}

Em sua obra A Corrosão do Caráter, Sennett (2009) nos ajuda a compreender um fenômeno que tem tomado proporções mundiais e firma-se como um dos grandes paradigmas da contemporaneidade. Trata-se do eloquente cenário em que os ideais de longo prazo são substituídos por buscas imediatas, assombradas pela falta de controle de tempo em uma época marcada pelo capitalismo flexível ${ }^{1}$. A partir das figuras de Rico e Enrico, filho e pai, o autor caracteriza dois distintos modelos de trabalhadores.

O trabalhador fordista, burocratizado e rotinizado, representado por Enrico, planejava sua vida e suas metas se baseando em um tempo linear, cumulativo e disciplinado. Suas expectativas profissionais e realização pessoal estão baseadas em metas longamente planejadas. Por outro lado, representado por Rico, o típico trabalhador da era do capitalismo flexível muda de endereço e de emprego frequentemente, não planeja suas metas a partir de expectativas de longo prazo e vive uma vida de incertezas na eloquente busca por uma rápida ascensão profissional e financeira (SENET, 2009).

Rico representa um novo modelo de sujeito, o qual Dardot e Laval (2016) chamam de “sujeito empresarial”, “sujeito neoliberal” ou, simplesmente, “neossujeito”. Essa nova figura opera uma unificação sem precedentes das formas plurais da subjetividade que a democracia liberal permitiu que se conservassem e das quais sabia aproveitar-se para perpetuar sua existência. Esse neossujeito tem total envolvimento com si mesmo. Dardot e Laval (2016, p.327) apontam que "a vontade de realização pessoal, o projeto que se quer levar a cabo, a motivação que anima o ‘colaborador' da empresa, enfim, o desejo com todos os nomes que se queira dar a ele é o alvo do novo poder”. Esse neossujeito apresentado por Dardot e Laval (2016) se autodefine quando resgatamos a afirmação de Teodoro (2011 p.55) de que "o neoliberalismo é, fundamentalmente, para além de uma ideologia e de uma propaganda, uma nova ordem social”, que resgata o poder de classe em face ao consumo.

O latente desejo de realização pessoal a qualquer custo motiva sua existência, suas ações e suas buscas. A pressa move esse desejo. Não há tempo a perder. Para explicar essas 
mudanças rápidas e significativas na vida das pessoas, típicas do que Bauman (2007) chama de “vida líquida”, Sennett (2009) reporta-se ao economista Bennett Harrison, o qual acredita que a origem dessa fome de mudança é o “capital impaciente”, ou seja, o desejo de retorno rápido. A ideia de sofrimento e resistência, representada na obra de Sennett (2009) pela figura de Enrico, que, pacientemente, economizou durante quinze anos para poder comprar sua casa própria, tornou-se algo “ultrajante e repulsivo” (BAUMAN, 2007).

Esse sujeito empresarial identifica-se constantemente com os termos "metas", “indicadores”, “resultados”, “eficácia”, que, reportados ao campo educacional, são muito empregados no discurso dos "empresários da educação” em congruência sistêmica ao que denominam "mercado educacional”. Esse recorrente discurso é amparado na normatividade de que o tempo da vida é cada vez menos linear, cada vez menos programável, onde o imperativo congênito da atualidade é o de que os ideais ou metas de longo prazo não existem mais. Segundo Dardot e Laval (2016), essa retórica tem aproximado os enunciados psicológicos e os enunciados econômicos até quase fundi-los, onde um conjunto de técnicas de diagnóstico e "ortopedia psíquica”, no campo educacional, profissional, e familiar, foi integrado ao grande dispositivo de eficácia das sociedades industriais.

Dessa forma, quando o estado não consegue dar conta das metas que lhe são estipuladas, principalmente em relação ao campo da educação, a iniciativa privada apresenta-se como alternativa amparada na lógica da eficácia e resultados. O discurso da iniciativa privada é atraente para o sujeito empresarial, pois é tomado de vocábulos que preenchem suas necessidades diante da nova ordem social. O que não se leva em consideração é que para atingir resultados e indicadores, a iniciativa privada, nem sempre possui compromissos em abarcar em seus empreendimentos educacionais aspectos fundamentais para a consolidação das sociedades democráticas. A diversidade, a inclusão e responsabilidade social podem sim sucumbir diante de mecanismos de seleção e exclusão, de programas padronizados para atingir a população mais apta a responder positivamente aos objetivos e metas esperadas.

Foi dentro deste contexto e com o objetivo de atender aos anseios do sujeito empresarial que surgiram, por exemplo, as charter schools americanas. Introduzidas inicialmente em Minnesota, em 1992, são financiadas com dinheiro público, mas gerenciadas de forma privada. Segundo Abrams (2016), essa modalidade de escola consolida as ideias de Friedman, que há décadas já recomendava que operadores com fins lucrativos administrassem escolas públicas como critério para elevar a qualidade do ensino. Em sua obra Education and the Commercial Mindset, Abrams (2016) aborda a atuação de uma série de empresas especializadas em administrar escolas americanas com fundos públicos. Entre as maiores, destaca a Edison Schools Inc., com sede no décimo quinto andar de uma torre de escritórios em Manhattan. Em 2001, a Edison já administrava uma rede de 114 escolas com 74.000 estudantes em 23 estados. Um pouco mais da metade dessas escolas eram escolas distritais, enquanto o restante eram escolas charter (ABRAMS, 2016).

A Edison, assim como as demais empresas do segmento, passaram a ser conhecidas como Educational Management Organizations (Organizações de Gerenciamento Educacional), ou apenas EMOs. A organização dessas empresas de serviços educacionais se espelhou nas Health Maintenance Organizations (Organizações de Manutenção de Saúde), 
ou HMOs, especializadas em administrar setores da saúde com fundos públicos. Com o mesmo pretexto das HMOs, as EMOs orientavam seu marketing com um discurso de "melhorar o serviço, conter custos e, em muitos casos, obter lucro" (tradução dos autores, ABRAMS, 2016, p. 9). Hoje, as escolas charter americanas compõem um universo de mais de 6 mil escolas em 42 estados.

O que Abrams (2016) destaca da experiência americana, Bunar (2012) também evidencia em seus estudos sobre o sistema educacional da Suécia, outro país que apostou muito em um modelo descentralizado e nas Charter Schools. Ambos constatam que, embora os aparentes resultados positivos das avaliações e rankings nacionais e das enfáticas defesas desses sistemas como modelos modernos e mais eficazes, há elementos contraditórios, que merecem estudo e publicidade. Conforme os autores, o estresse ligado à escolha da escola pela família, o tempo excessivo dedicado ao marketing e a inflação de notas, como forma de melhorar a posição de uma escola no mercado resultaram em significativos indicadores de aumento de mecanismos socialmente injustos e segregadores do sistema educacional, que em sua construção sócio-histórica deveria conceber uma educação pautada pelo princípio do bem comum (DARDOT; LAVAL, 2017).

Apesar de outros países Latino Americanos terem adotado essa modalidade escolar em maior escala, todos sob influência do modelo americano, como é o caso do Chile (ELACQUA, 2009) e da Colômbia (EDWARDS JR. ; HALL, 2017), no Brasil, pouco se tem registrado sobre tal temática ou iniciativas dessa natureza organizacional. A carência de registros de tal iniciativa no Brasil é constatada por Adrião (2014), que em levantamento sobre publicações brasileiras no Scielo e Banco de Tese da Capes, referentes ao período de 1990 a 2012, que tenham adotado como palavras-chave (descritores) os termos charter ou choice associadas à educação, constatou a inexistência de publicações sobre a temática.

No entanto, Adrião (2014) ressalta que, por outro lado, o que a literatura e os manuais consultados para a pesquisa realizada caracterizam por charter, pode englobar tanto escolas públicas geridas por instituições privadas, quanto escolas privadas subsidiadas por fundos públicos. Todavia, "as condições exigidas para que tais escolas sejam charter é que não haja cobrança de mensalidades ou matrículas, que operem segundo as normas estabelecidas pelos setores responsáveis e que possam ser escolhidas pelas famílias” (ADRIÃO, 2014, p. 278). Dessa forma, o estudo de Adrião (2014) questiona se não seriam as escolas "conveniadas" brasileiras, tão disseminadas e mesmo induzidas por diversos programas governamentais para o atendimento da educação básica uma modalidade de charter. Adrião (2014) também atenta para a possibilidade de estarmos vivenciando a experiência do modelo escolar americano com outra designação, porém com os mesmos problemas denunciados por Abrams (2016), Bunar (2012), Elacqua (2009) e Edwards Jr. e Hall (2017).

Convém destacarmos que essas parcerias se intensificaram a partir do novo Marco Regulatório do Terceiro Setor, através da Lei ${ }^{0}$ 13.019/14, que cria as Organizações da Sociedade Civil - OSC. Por consequência da nova legislação e também de leis anteriores que continuam regulando boa parte dessas parcerias, como a chamada Lei das Organizações Sociais (Lei 9.637 de 15 de maio de 1998), que compreende entidades de caráter privado, mas que ganham esse status social caso cumpram uma série de requisitos, como eficácia comprovada e fins sociais, o 
poder público acaba não conseguindo exercer uma fiscalização e monitoramento adequado dessas relações, tendo em vista a sua complexidade (PIRES; PERONI; ROSSI, 2017). Essa nova legislação (OSC) começou a vigorar em janeiro de 2016, nos âmbitos da União, Estados e Distrito Federal. Para os Municípios, foi estabelecido o início de sua vigência para $1^{\circ}$ de janeiro de 2017. É importante frisar que nesse novo modelo de parceria, a gestão das finanças, a contratação de professores e as questões pedagógicas são de responsabilidade do parceiro privado (PIRES; SUSIM; MONTANO, 2018).

Esse cenário materializa-se, sobretudo, pela pronta emergência do neoliberalismo pedagógico, que através da mercantilização da educação tem experimentado esses modelos de gestão educacional baseados nos ditames da chamada "Nova Gestão Púbica”, uma política que tem como princípio um Estado administrativo ao estilo da iniciativa privada ${ }^{2}$. Esse modelo de gestão prioriza resultados, redução do poder da burocracia estatal e a focalização na eficiência dos serviços. Tal prerrogativa, como avaliaremos a seguir, tem provocado um aumento significativo de parcerias entre o público e o privado na área educacional, de modo que em alguns casos, a fusão é tão grande que dificulta a identificação das fronteiras entre o que é mercado e o que é escola, revelando um primeiro e perigoso diagnóstico dessas "parcerias".

\section{O neoliberalismo pedagógico como produto do sujeito empresarial}

A internacionalização das políticas educacionais, por meio do financiamento competitivo e contratual da educação, com foco em resultados, tem impactado diretamente na gestão da educação e na qualidade dos serviços educacionais prestados pelos estados. A fragilidade de alguns estados-nações em gerenciarem a eficácia de seus sistemas educacionais diante dos desafios da globalização, faz com que alguns organismos internacionais passem a determinar metas que os países devem atingir em matéria de educação, com fundamentação nos interesses de uma economia de mercado. Entre esses organismos podemos citar a Organização dos Estados Americanos (OEA), Banco Interamericano de Desenvolvimento (BID), Banco Mundial (BM), Organização de Cooperação e Desenvolvimento Econômico (OCDE), Fundo Monetário Internacional (FMI), entre outros. Enquanto esses organismos econômicos aumentam suas influências na elaboração das políticas educacionais, ao mesmo tempo assistimos a UNESCO, órgão responsável por auxiliar os países a promoverem o acesso e a qualidade da educação em todos os níveis e modalidades, perder sua capacidade de orientar os rumos da internacionalização das políticas para a educação.

Alguns desses organismos, ligados à economia, chegam até mesmo a assumir, embora de forma oculta, o papel que seria dos ministérios de educação, sobretudo no caso dos países em desenvolvimento, como é o caso do Brasil. Dessa forma, a necessidade de apresentar resultados que vão ao encontro das metas estipuladas por essas instituições faz com que se acentue um processo de canalização de recursos a modelos de gestão educacional que priorizem o desenvolvimento econômico. Assim, ganham espaço na formação dos 
profissionais da educação, a instrumentalização de funcionários/agentes para o mercado educacional.

Diante desse contexto, a compreensão sócio histórica da docência pautada por um ideal de caráter comum, com uma concepção de educação para todas as crianças intrinsicamente de valor igual, abre espaço para uma concepção que prioriza a performance individual das escolas e dos alunos, para processos de diferenciação e hierarquias, de canalização, seleção e exclusão. Além disso, de acordo com Ball e Youdell (2007), a educação no contexto do mercado objetiva atrair clientes, ocasionais e regulares, com ênfase sobre a atribuição de recursos àqueles considerados mais aptos a atingirem metas e a educação das crianças é avaliada com base nos custos e resultados.

Tello (2013) considera que a década de 1990 representa o marco inicial dessa política mundial, emanada do documento de Jontiem (Tailânda), quando se cristaliza uma série de transformações, através das quais têm origem profundas mudanças nas esferas políticas, econômicas e sociais nos países e região. Essas transformações provocaram impactos, transformaram e redesenharam a esfera educativa principalmente por meio das reformas e pós-reformas nos sistemas educacionais na América Latina, estreitamente vinculadas aos processos de reestruturação das economias nacionais. As perspectivas outorgadas à profissionalização docente na América Latina se converteram em um espaço de confrontação com implicações para a prática e a política educativa que se desdobram em perspectivas discursivas divergentes e antagônicas, materializadas nas metas, currículos e nos sistemas educacionais dos países. Ao considerarem metas globalmente estipuladas, os sistemas educacionais desconsideram as peculiaridades regionais, as necessidades locais particulares de cada país.

Além disso, uma das principais características do neoliberalismo pedagógico está em suas matrizes curriculares, renunciando imprudentemente às competências que são indispensáveis à sobrevivência das sociedades democráticas, como as disciplinas relacionadas às artes e às humanidades. Se por um lado são reduzidas disciplinas que favorecem a construção de um pensamento crítico, por outro lado são ampliadas disciplinas de ordem teórica e tecnológica, por exemplo. Para Nussbaum (2015, p.21) se esta tendência persistir, em breve vão produzir-se pelo mundo inteiro gerações de "máquinas úteis, dóceis e tecnicamente qualificadas”, em vez de cidadãos realizados, capazes de pensar por si próprios, de pôr em causa a tradição e de compreender o sentido do sofrimento e das realizações dos outros. Ela considera que as mudanças nos currículos, eliminando disciplinas das humanidades, implicam justamente na direção apontada de preparar um "conjunto de trabalhadores obedientes, tecnicamente treinados para executar os projetos das elites, que visam o investimento externo e o desenvolvimento tecnológico” (NUSSBAUM, 2015, p. 21). Nesse sentido, toda política que represente um fomento à liberdade de pensamento dos alunos, constitui-se como uma ameaça.

Quando se prioriza uma educação incapaz de atingir uma população em sua diversidade cultural, étnica e econômica, que coloca como princípio o desenvolvimento econômico, se reproduz um sistema desigual. Vale destacar o exemplo da África do Sul, que durante o Apartheid, apresentava índices extremamente positivos de desenvolvimento da economia, 
porém, a realidade social do país materializava diferenças gritantes. Para Nussbaum (2015), nenhum sistema educacional funciona bem se seus benefícios só alcançam as elites abastadas.

Quando um modelo de educação mira o desenvolvimento econômico ao invés do social, abre-se espaço a emergência de modelos educacionais que concebem a escola como uma empresa, onde os alunos assumem o papel de clientes. Para Bittencour (2014, p. 250), nesse cenário, no que se refere à educação privada em larga escala "a relação pedagógica entre professor e aluno se converte em uma relação comercial, na qual o docente se encontra na obrigação de, tal como um vendedor de conhecimento, satisfazer todos os caprichos de seu cliente”. Dessa forma, o próprio processo de ensino se flexibiliza e pode se tornar cada vez menos exigente intelectualmente. Além disso, com atividades cognitivas cada vez mais superficiais, visa modelar o estudante para um mercado de trabalho que exige a supressão da identificação existencial com seu oficio.

Esse modelo mercantil de escola permite a compreensão de que não é por acaso que a educação tem assumido esse papel diante dos anseios desse modelo econômico. A educação parece estar, como já apontado, há alguns anos na mira do setor privado e, desse ponto de vista, constitui-se no grande mercado do século XXI. De acordo com Akkari (2011), os bilhões de dólares gastos anualmente pelos estados e pelas famílias na educação instigam esse interesse. Trata-se de um mercado garantido e inesgotável. Esse novo mercado tem atraído o capital externo e influenciado na elaboração de políticas educacionais que favorecem a perpetração do setor privado sobre o público, eliminando fronteiras, fortalecendo o neoliberalismo pedagógico e viabilizando a privatização da educação e de uma série de serviços que circundam ao seu redor, como analisaremos a seguir

\section{A extinção das fronteiras entre o público e o privado}

O neoliberalismo pedagógico abre espaço para a privatização da educação em diferentes níveis e de formas, muitas vezes, camufladas sob a designação genérica de “educação”. Dentro deste campo amplo, circundam muitos serviços paralelos, como apostilamento, alimentação, instalações desportivas e aconselhamento psicológico e vocacional, que podem ser contratados por empresas privadas, especializadas em ofertar tais serviços. Uma vez que estes prestadores "se revelarem mais eficientes, então os governos poderão querer encorajar esta opção. Esta poderá ser a abordagem mais frequente e menos polêmica da privatização da educação” (BELFIELD e LEVIN, 2004, p. 32).

Para Akkari (2011) a disseminação desses novos paradigmas e conceitos que supostamente dariam maior eficácia às políticas educacionais incidem, sobretudo, nos seguintes aspectos: adaptação indispensável à globalização econômica; benefícios da tecnologia da informação e comunicação na educação; descentralização; privatização da educação; obrigação de resultados e prestação de contas; boa governança; qualidade da educação; reformas curriculares; padrões educacionais; profissionalização docente.

Sobre esses aspectos, Ball e Youdell (2007) consideram que não se trata do abandono por parte do estado do controle que ele exerce sobre os serviços públicos de educação, mas 
o estabelecimento de uma nova forma de controle ou de uma redução controlada desse controle, o que favorece a descentralização e a perpetração do setor privado sobre o público. Isso só é possível, segundo Akkari (2011) com o declínio da qualidade das escolas públicas; desenvolvimento da educação permanente por meio de políticas públicas ou por empresas (subsídios para a formação continuada); homogeneização dos conteúdos de ensino, permitindo o aumento do mercado de livros didáticos e de softwares.

Esses indicativos reforçam a tese de que a escola configura-se como um grande mercado. Dessa forma, a rede privada, por exemplo, ataca o mercado de publicação educacional com foco nos milhões de alunos de escolas públicas. Segundo Akkari (2011), essa tendência é facilitada pela fragilidade do setor de publicação educacional público no Brasil, comparado ao de países emergentes como Índia, China ou Indonésia. As fragilidades estão localizadas na falta de controle social, técnico, pedagógico e financeiro e pelo reforço na padronização de conteúdos e de programas, justificadas pelo discurso da garantia mínima de qualidade.

Em convergência a este cenário, Adrião e Peroni (2009) afirmam que esse processo de perpetração do setor privado sobre o público no âmbito da educação pode ser processado por meio da adoção de distintas políticas de convênio e parcerias. Como exemplos, destacam a compra de material apostilado, a aquisição de sistemas de gestão elaborados por instituições com ou sem fins lucrativos, a ampliação das matrículas custeadas por recursos públicos em instituições privadas e a terceirização de merendas e contratação de funcionários que não integram o quadro do magistério.

Os exemplos dessas políticas são recorrentes. Medidas como a reforma do ensino médio proposta pelo governo Temer em 2016, através de Medida Provisória (MPV 746/2016), podem ser ferramentas de consolidação dessas práticas, uma vez que muitos pontos da reforma ainda carecem melhor elucidação. Exemplo disso é a possibilidade de contratação de profissionais de "notório saber”, o que ainda paira muitas dúvidas sobre quem seriam esses profissionais. Segundo o MEC, profissionais sem licenciaturas que poderiam lecionar disciplinas técnicas profissionalizantes. Entendemos que essa reforma também vai ao encontro do Projeto Lei da Terceirização ( $n^{0}$ 13.429/2017), que permite a contratação terceirizada de trabalhadores em todas as atividades, inclusive na docência.

Outro fator relevante pode ser observado no Rio Grande do Sul. No ano de 2016, o governo do estado sancionou a Lei $\mathrm{N}^{0}$ 12.234, de 13 de janeiro de 2005, que dispõe sobre normas para licitação e contratação de parcerias público-privadas, institui o Programa de Parcerias Público Privadas do Estado do Rio Grande do Sul - PPP/RS. Já no ano de 2017, com amparo legal, um programa da Secretaria Estadual de Educação envolveu 700 escolas, que receberam recursos superiores a R\$ 2 milhões em doações, oriundos de 411 parcerias com o setor privado. O Programa Escola Melhor, Sociedade Melhor, da Secretaria Estadual de Educação, foi criado com a intenção de estabelecer parcerias público-privadas para construções de áreas cobertas, manutenções prediais, coberturas de acesso, plataformas de acessibilidade para os alunos com deficiência, materiais de sala de aula e de informática. O número de Escolas que aderiram ao programa no ano de 2017 foi 50\% superior ao registrado em 2016. 
O ponto central desta parceria estabelecida pelo programa do governo gaúcho está na contrapartida ofertada a essas "empresas parceiras”. Cada uma delas recebeu o direito de explorar espaços publicitários dentro das instituições de ensino, bem como de divulgar e oferecer seus produtos aos alunos e à comunidade escolar. Para Laval (2004, p.135), “a comercialização do espaço escolar é um dos aspectos mais significativos do desaparecimento das fronteiras entre escola e sociedade de mercado". Segundo o autor, esse quadro é uma representação clara da liquefação progressiva dos quadros mentais e ideológicos da escola, os quais durante muito tempo garantiram o distanciamento entre publicidade e educação, fazendo assim com que a lógica comercial e ensino parecessem estranhos um ao outro.

Essa prática vem sendo utilizada na América do Norte há muito tempo. Laval (2004) cita um exemplo dos anos 1990, onde para obter material de informática que lhes faltava, 450 escolas no Quebec se inscreveram no concurso “A educação acima de tudo” da empresa de cereais Kellog. Conforme Laval (2004), a finalidade do jogo é conseguir o maior número de provas de compras de qualquer um dos produtos da marca, desde os cereais mais clássicos até os mais exóticos. O prêmio aos vencedores era de quarenta mil dólares em materiais e programas. Diante de tal potencial de atratividade para escolas e alunos tal prática se transformou num fenômeno americano definido como “alunos à venda" demonstrando o poder e a potência da publicidade nas escolas (LAVAL, 2004, p.139).

Os exemplos dessas parcerias entre o setor público e o privado acumulam exemplos ainda mais assombrosos e pretenciosos. Laval (2004) registra o caso de alunos americanos que são obrigados a assistir diariamente um programa de televisão em troca de apoio financeiro para as escolas. O exemplo vem da parceria estabelecida pelas escolas com um dos mais conhecidos programas de marketing escolar, o Canal Um, criado pelo executivo Chris Whittle em $1989^{3}$. Essa postura beira à doutrinação. Está de acordo com a ideologia do Free Market que não conhece nenhuma limitação, nenhuma fronteira. Nesse cenário, faz sentido a afirmação de Laval (2004), que as vantagens servem somente para os partidários do livre mercado.

Outro exemplo é o "Projeto Piloto de Alfabetização de Crianças com Seis Anos", desenvolvido pelo governo do estado do Rio Grande do Sul ainda no ano de 2007, durante gestão da governadora Yeda Rorato Crusius (PSDB), cujo espectro partidário apoia-se nos preceitos do neoliberalismo. O projeto foi desenvolvido, principalmente, por institutos como o Ayrton Senna, de São Paulo e o Alfa e Beto, de Minas Gerais. Ainda, houve a participação da Fundação Cesgranrio, responsável pela avaliação. Na época, essa parceria foi implantada em 600 turmas de $1^{\circ}$ ano das redes públicas municipais e estadual do Rio Grande do Sul, conforme apontam os dados então divulgados no site da secretaria ${ }^{4}$.

Podemos identificar nesse programa parcerias público/privadas em quatro esferas: na gestão, fornecimento de materiais, capacitação dos professores e avaliação. A gestão do programa, como informado na reportagem, ficou sob responsabilidade da SEC, em conjunto com a Unesco e com a Undime/RS (União Nacional dos Dirigentes da Educação. As cartilhas [materiais] foram fornecidas pelos programas no momento da execução do contrato. No pacote estão cartilhas para alunos, materiais para o professor e jogos pedagógicos. Para o adequado uso desse material, o instituto oferece no contrato com os municípios e o estado o 
treinamento ou capacitação dos professores. Por fim, ainda integra o conjunto de produtos e serviços contratados a avaliação periódica do desenvolvimento do projeto, apresentando indicadores de desempenho dos alunos ao contratante.

Essa prática ainda adotada em municípios do Rio Grande do Sul e divulgada com muito entusiasmo pelos gestores municipais, implica diretamente no desenho da política educacional. Segundo Adrião e Peroni (2009), geralmente, esses projetos partem de um diagnóstico de que os professores não são capazes de planejar suas tarefas e por isso devem receber tudo pronto. Além de subestimar a capacidade dos professores com materiais prontos, esses municípios, muitas vezes, acabam ignorando ou até mesmo descartando os livros oriundos do Programa Nacional do Livro Didático (PNLD), gerando assim um gasto duplo e desnecessário aos cofres do estado. De acordo com Adrião (2008), essas parcerias públicoprivadas vigentes na educação básica materializam tanto a proposta do público não estatal, quanto a do quase-mercado, pois uma vez que o setor público assume uma lógica de gestão proposta pelo setor privado, acaba assumindo mesmo que de forma oculta os interesses e anseios do mercado.

No âmbito da gestão escolar, esse diagnóstico fica ainda mais visível. Vide o exemplo da parceria firmada entre o governo do estado do Paraná com a Klabin Celulose - maior produtora e exportadora de papéis do Brasil - para a gestão de 31 escolas estaduais. O projeto de gestão educacional desenvolvido em parceria com Klabin envolve 31 escolas da região dos Campos Gerais, onde a empresa tem duas fábricas. Conforme o governo paranaense, “a proposta é melhorar os resultados do ensino por meio da gestão das escolas e do aprendizado em sala de aula e, em consequência, elevar o desempenho no Ideb (Índice de Desenvolvimento da Educação Básica)”, conforme notícia veiculada pela Agencia de Notícias do Paraná . O projeto, que envolve 11 mil alunos, prevê que a empresa, entre 2017 e 2018, invista R\$ 2 milhões na formação continuada de cerca de 890 profissionais da educação. O Governo do Estado cede a estrutura e disponibiliza os profissionais. A condução do projeto é de curadoria do Instituto Falconi, especializado em consultoria de gestão para órgãos públicos e privados.

Essa parceria, vista com méritos pelo governo do estado, é um retrato fiel da política educacional que vigora como resultado da aquisição de uma cesta de produtos ou insumos adquiridos no mercado educacional. Esse tipo de política, como expressado por Adrião (2008, p.8), “além de não resultar de discussões com a comunidade escolar, dado ser definida em função de um padrão construído pelo agente privado, redefine o espaço do público e minimiza sua autonomia diante do privado"

Se por parte do governo paranaense a proposta é vista com bons olhos, o mesmo não acontece por parte dos professores envolvidos no projeto. Em nota publicada em 05 de julho de 2017, a APP - Sindicato dos Trabalhadores em Educação Pública do Paraná - manifestou sua contrariedade à parceria, afirmando que "acredita que mercantilizar as relações de ensino e aprendizado é um dos elementos que consolidam a manipulação da população e fortalecem os governos antidemocráticos”6. 
Figura 01: Título e ilustração usada na nota emitida pela APP

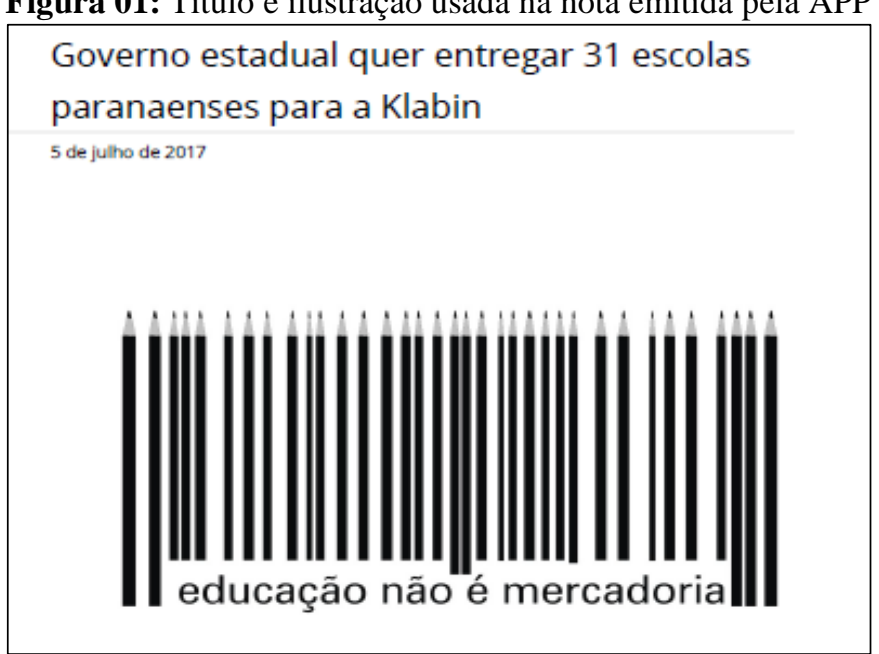

Fonte: APP - Sindicato dos Trabalhadores em Educação Pública do Paraná

A posição dos professores é ainda mais enfática quando aborda os mecanismos de avaliação empregados pela parceria entre o governo e a Klabin:

Para um governo que mensura qualidade da educação exclusivamente pelo Ideb, não faz sentido discutir a qualidade educacional, a individualidade do(a) estudante, os direitos dos(as) trabalhadores(as) e também a evasão escolar assuntos tão estudados e debatidos no ambiente sindical. Nessa lógica mercadológica, quem não dá resultado tem que estar fora. É a volta do projeto Adote uma Escola. É uma forma de coisificar todos os(as) estudantes que estão lá dentro e também os(as) trabalhadores(as) (APP, 2017).

Parcerias como esta firmada entre o Governo do Paraná e a Klabin, reforçam a denúncia de Adrião (2014), de que estaríamos vivenciando a experiência charter americana com outra designação, porém com os mesmos problemas relatados por Abrams (2016), que consistem, sobretudo, em mecanismos socialmente injustos e segregadores, consolidando as ideias de Friedman, que há décadas já recomendava que operadores privados, com fins lucrativos, administrassem escolas públicas como critério para elevar a qualidade do ensino.

Esse modelo de gestão educacional baseada em princípios do mercado retoma o que Ball e Youdell (2007) definem como prática que objetiva atrair clientes, ocasionais e regulares, com ênfase sobre a atribuição de recursos àqueles considerados mais aptos. As avaliações são restritas do mérito, com base na contribuição dos indicadores de desempenho e a educação das crianças é avaliada com base nos custos e resultados. Este modelo abre espaço para a performance individual das escolas e dos alunos, para processos de diferenciação e 
hierarquias, de canalização, seleção e exclusão, representando um grande risco ao princípio democrático de educação, de caráter igual e acessível a todos.

No contexto dessas parcerias, Dardot e Laval (2016) consideram que toda a reflexão sobre a administração pública adquire um caráter técnico, em detrimento das considerações políticas e sociais que permitiriam evidenciar tanto o conceito da ação pública como a pluralidade das opções possíveis. Essa prerrogativa afeta diretamente a própria concepção dos bens públicos bem como os princípios regentes de sua distribuição. "A igualdade de tratamento e a universalidade dos benefícios são questionadas tanto pela individualização do auxílio e pela seleção dos beneficiados, na qualidade de amostras de um 'público-alvo', quanto pela concepção consumista do serviço público” (DARDOT; LAVAL, 2016, p. 380).

Além desses modelos e exemplos de perpetração do setor privado sobre o público do âmbito da educação, existe ainda outra forma pela qual o campo educacional tem se curvado aos ditames das parcerias entre o público e o privado. Esta se refere ao financiamento ou subvenção por parte do poder público a escolas e/ou instituições privadas com e sem fins lucrativos. A justificativa para tal parceria recorre à necessária efetivação do direito à educação básica, obrigatória a partir dos 4 anos, razão pela qual se generalizam programas de compra de vagas em escolas privadas em substituição à ampliação das vagas em escolas públicas, principalmente em relação à educação infantil.

Neste caso, temos o exemplo concreto do governo do município de Santa Maria - RS, que só no ano de 2016, conforme mostra estudo de Possebon (2016), comprou 759 vagas para alunos de educação infantil na rede privada de ensino a um custo de mais de R\$ 2,8 milhões. A medida foi uma saída encontrada para atender o déficit na oferta de vagas na rede pública municipal. Porém, o histórico dos valores gastos com a compra de vagas na rede privada, mostra que o montante dos valores representa "uma quantia razoável para expandir as estruturas físicas da rede municipal ou a sua ampliação através de novas escolas, se tais estratégias estivessem no planejamento do município” (POSSEBON, 2016, p. 85).

Exemplos como este do governo de Santa Maria- RS tem se ampliado tanto que acabam comprometendo as próprias estatísticas educacionais, uma vez que os municípios contabilizam como pública a vaga contratada junto à instituição privada. Para Adrião (2008), esse movimento indica uma preocupante ampliação do atendimento à demanda custeada por recursos públicos, mas subsumida à ampliação e à disponibilidade do setor privado.

Esse flerte entre o público e o privado no âmbito da educação tem aumentado em proporções gigantescas e legitimado as previsões já subscritas de Akkari (2011) e Laval (2004) de que a educação é o grande mercado do século XXI. Esse processo todo, como bem abordado por Dardot e Laval (2016, p.168) tem provocado "uma reelaboração da questão da liberdade e dos direitos individuais”, já que regras dessa natureza tornam possível “a formação da ordem espontânea do mercado, uma extensão do 'domínio' da liberdade individual”.

Quando as fronteiras entre o público e o privado emergem neste efeito degradê, a democracia educacional coloca-se em risco. Esse efeito não representa o total abandono por parte do estado do controle que ele exerce sobre os serviços públicos de educação, mas sim, como já falamos, trata-se de uma redução calculada desse controle, com vistas justamente 
aos mecanismos que favorecem a descentralização e a perpetração do setor privado sobre o público. Como a lógica do mercado é a do lucro, qualquer função que não lhe proporcionar as vantagens esperadas, não lhe despertará o interesse e muito menos investimentos.

\section{Considerações importantes}

Com vistas ao exposto, o "capital impaciente” que mobiliza as ações do sujeito empresarial descrito por Dardot e Laval (2016), é o mesmo que move os anseios dos empresários da educação. O latente desejo de retorno rápido, tipicamente associado aos vocábulos deste campo léxico, tais como "metas”, “indicadores”, "resultados”, “eficácia”, sustenta e alimenta a voracidade com que o neoliberalismo pedagógico ataca o ensino público. A promessa de que uma educação de qualidade é medida por números e indicadores pode esconder desigualdades que legitimariam o esmaecer da democracia educacional.

Assim, reiteramos a constatação de Adrião (2008) de que quando os elementos fundamentais da prática educativa estão sob o poder do setor privado, tais como os recursos pedagógicos, a gestão e as avaliações institucionais, o caráter público e democrático da educação é colocado em xeque. Esse quadro, retomando Laval (2004), representa a clara liquefação progressiva dos quadros mentais e ideológicos da escola, histórico e socialmente constituídos. Nas mãos do setor privado, esses elementos deixam de ser concebidos a partir da lógica do ensino público para dar lugar a um caráter eminentemente mercantil. Em um cenário favorável ao discurso neoliberal da eficácia e eficiência, concretizado pela inoperância do estado, abrem-se demasiadamente as portas da escola para a mercantilização da educação.

É importante reafirmarmos que uma educação sob a égide da iniciativa privada, necessariamente, não possui compromissos com aspectos fundamentais para a consolidação das sociedades democráticas. A diversidade, a inclusão e responsabilidade social ficam em segundo plano diante de mecanismos de seleção e exclusão, de programas padronizados para atingir um maior número de alunos a um menor custo. A política operacional da iniciativa privada no campo da educação, como bem expressado por Adrião (2008), elimina discussões com a comunidade escolar e minimiza a autonomia do espaço público diante do privado. Em síntese, torna menos do povo o que por direito deveria ser do povo: uma educação igual e de qualidade para todos.

Além disso, deve ser questionado esse discurso de que a educação sob os ditames do setor privado e com um sistema educacional mais descentralizado teria grandes possibilidades de atingir melhores resultados em avaliações de larga escala. Assim como Bunar (2012) mostra em seus estudos sobre o modelo educacional da Suécia, que apostou em uma descentralização e nas escolas charter, dados do relatório da OCDE de 2010 mostram que o país, vinte anos depois da implantação dessas políticas neoliberais, não diminuiu os custos do sistema educacional e que as notas nas escolas de ensino fundamental e médio estão em constante declínio. Além disso, o relatório mostra que a Suécia perdeu terreno em estudos comparativos internacionais, como o PISA e o TIMSS (OCDE 2010). 
Esses dados fazem perder sustentação o argumento de muitos gestores, de empresários da educação e de políticos, de que a iniciativa privada oferece uma educação com mais qualidade do que a esfera pública.

Nesse sentido, também merecem destaque dados como os da Finlândia, reconhecida internacionalmente pela qualidade da sua educação pública e pelo bom posicionamento nos rankings internacionais. Conforme Abrams (2016), o país nórdico, diferentemente do seu vizinho do sul, a Suécia, apostou fortemente em uma educação pública e na formação de seus professores como profissionais de ensino, com uma consistente proposta de formação pedagógica e com acompanhamento profissional nas escolas. Além do prestigio social da profissão e da valorização do governo para com esses profissionais do ensino, a confiança que as famílias depositam na escola pública e nos professores são ingredientes que fazem com que o país se destaque na área, provando que uma educação de qualidade não está relacionada simplesmente à atuação da esfera pública ou privada. Uma educação de qualidade está diretamente relacionada à proposta de ensino que ser quer colocar em prática, se visa o bem-estar social da população ou simplesmente a instrumentalização do sistema educacional para o atendimento às demandas do setor empresarial ou de grupos políticos, seja de esquerda ou de direita.

Dar conhecimento à sociedade das implicações destes processos é fundamental para que se possa preservar e democracia educacional e o direto a todos de uma educação intrinsicamente de valor igual. Enquanto o estado gasta milhões de reais com a aquisição de produtos pedagógicos padronizados junto à iniciativa privada, além de subestimar a capacidade dos professores e de anular a singularidade dos alunos, perde a grande oportunidade de investir na produção de material humano e pedagógico com vistas a uma educação pública de qualidade.

Além disso, é importante lembrar que muitas parcerias público-privadas instauram-se, cordialmente e informalmente, muito antes mesmo da composição oficial dos governos. Afinal, como tem se revelado constantemente, no Brasil, muitas doações de campanhas eleitorais efetivadas por empresas privadas resguardam uma intencionalidade oculta para fins futuros. Mas isso é assunto para outro ensaio.

\section{Notas}

1. Sennett (2009) considera que o caráter flexível do capitalismo tem como consequências a exigência à negação das formas rígidas da burocracia bem como a alteração dos significados do trabalho e a ampliação exacerbada de suas jornadas. Essas exigências de flexibilidade na atuação profissional associada à inexorável fugacidade das relações trabalhistas estariam contribuindo para enfraquecer valores como o compromisso, a confiança e a lealdade, que são fundamentais para a consolidação do caráter humano.

2. Constituem ideias centrais da Nova Gestão pública um Estado administrativo ao estilo da iniciativa privada; contratos de gestão entre unidades; avaliação de desempenho; ênfase em resultados; redução do poder da burocracia; focalização na eficiência; busca de mecanismos regulatórios; introdução sistemática de conceitos de produtividade; flexibilidade; competitividade administrada; participação dos agentes sociais e controle dos resultados; foco no cidadão, orçamento e avaliação por resultados e performance; fortalecimento e aumento da autonomia da burocracia; descentralização na formulação e execução de políticas e por fim maior autonomia às unidades executoras (ARAÚJO, 2010, p. 145). 
3. Por contrato, as 12.000 escolas elementares e médias que aceitaram receber o programa (o número é dado pela firma, a qual tem interesse em expandir) aceitaram fazer com que os alunos assistam a cada dia, pelo menos 12 minutos de programas - ou seja, o equivalente a seis dias de aula por ano - contendo vários spots intercalados, representando dois minutos de publicidade por dia, em $90 \%$ dos dias de aula e em $80 \%$ das classes da escola. Atualmente, 8 milhões de escolares americanos são submetidos a esse tratamento e transformados em 'público cativo', sobretudo nas escolas mais desguarnecidas que estão escolarizando os meios pobres e as minorias étnicas (LAVAL, 2004, p. 139).

4. Ver: <http://servicos.educacao.rs.gov.br/pse/srv/noticias_det.jsp?PAG=1118\&ID=2539>, acesso em 05 de março de 2018.

5. Disponível em: http://www.aen.pr.gov.br/modules/noticias/article.php?storyid=94466\&amp;tit=Governo-e-Klabinfirmam-parceria-em-projeto-de-gestao-escolar, acesso em 11 de março de 2018.

6. Disponível em: http://appsindicato.org.br/governo-estadual-quer-entregar-31-escolas-paranaenses-para-a-klabin/, acesso em 11 de março de 2018.

\section{Bibliografia}

ABRAMS, Samuel E. Education and the Commercial Mindset. Cambridge, Massachusetts: Harvard University Press, 2016.

ADRIÃO, Theresa. Sistemas apostilados de ensino e municípios paulistas: o avanço do setor privado sobre a política educacional local. In Anais do V Simpósio internacional: o estado e as políticas educacionais no tempo presente. UFU/Uberlândia, 2008.

ADRIÃO, Theresa; PERONI, Vera. A educação pública e sua relação com o setor privado: implicações para a democracia educacional. Revista Retratos da Escola, 2009, p.107-116.

BITTENCOURT, Renato Nunes. A mercantilização educacional e a ideologia do ensino espetacular. In: Revista Lugar Comum. No 43. Rio de Janeiro: UFRJ, 2014.

AKKARI, Abdeljalil. Internacionalização das políticas educacionais: transformações e desafios. Petrópolis - RJ: Vozes, 2011.

ARAÚJO, Maria Arlete Duarte. Responsabilização da administração pública: limites e possibilidades do gestor público. In: Construindo uma Nova Gestão Pública - Coletânea de textos do I Ciclo de Palestra organizado pela Escola de Governo do RN -Natal, RN: SEARH/ RN, 2010.

BALL, Stephen J; YOUDELL, Deborah. Privatización encubierta en la educación pública. In: Anais do V Congreso Mundial de la Educación. 2007.

BELFIELD, Clive R; LEVIN, Henry M. A Privatização da Educação: causas e implicações. Porto: ASA, 2004.

BAUMAN, Zygmunt; Vida Líquida. Trad. Carlos Alberto Medeiros. Rio de Janeiro: Jorge Zahar Ed., 2007;

BUNAR, Nihad. Parents and teachers on local school markets: Evidence from Sweden. Working Paper 208, National Center for the Study of Privatization in Education, Teachers College, Columbia University, 2012.

DARDOT, Pierre; LAVAL, Christian. A Nova Razão do Mundo: ensaio sobre a sociedade neoliberal. Trad. Mariana Echalar. São Paulo: Boitempo, 2016.

EDWARDS JR, D. Brent; HALL, Stephanie M. Colombian Charter School Management. Working Paper 234, National Center for the Study of Privatization in Education, Teachers College, Columbia University, 2017.

ELACQUA, Gregory. The impact of school choice and public policy on segregation: Evidence from Chile. Working Paper 185, National Center for the Study of Privatization in Education, Teachers College, Columbia University, 2010.

LAVAL, Christian. A Escola não é uma Empresa: o neoliberalismo em ataque ao ensino público. Trad. Maria Luiza M. de Carvalho e Silva. Londrina: Planta, 2004.

NUSSBAUM, Martha. Sem Fins Lucrativos: Por que a democracia precisa das humanidades. Trad. Fernando Santos. São Paulo: Martins Fontes, 2015.

ORGANIZATION FOR ECONOMIC CO-OPERATION AND DEVELOPMENT — OECD. Making reform happen: lessons from OECD countries. Paris: OECD Publishing, 2010. 
PIRES, Daniela de Oliveira; PERONI, Vera Maria Vidal; ROSSI, Alexandre Jose. Regulamentação do terceiro setor no Brasil e a democratização da educação pública. In.: Políticas Educativas, Santa Maria, v. 10, n. 2, p. 81-98, 2017.

PIRES, Daniela de Oliveira; SUSIM, Maria Otília Kroeff; MONTANO, Monique Robain. A configuração político-normativo da parceria público-privada: implicações na oferta da educação infantil no município de Porto Alegre. In.: Currículo sem Fronteiras, v. 18, n. 1, p. 239-268, jan./abr. 2018.

POSSEBON, Camila Moresco. Matrícula obrigatória na Educação Infantil: impactos no município de Santa Maria RS. Dissertação de Mestrado: UFSM, 2016.

SENNET, Richard. A Corrosão do Caráter: consequências pessoais do trabalho no novo capitalismo. Rio de Janeiro: Record, 2009.

SECRETARIA DA EDUCAÇÃO DO RIO GRANDE DO SUL. Escolas da rede pública estadual receberam R\$ 2 milhos em doações para infraestrutura. Disponível em: <http://www.educacao.rs.gov.br/escolasda-rede-publica-estadual-receberam-r-2-milhoes-em-doacoes-para-infraestrutura $>$. Acesso em: 05 de março de 2018.

GOVERNO DO ESTADO DO PARANÁ. Governo e Klabin firma parceria em projeto de gestão escolar. Disponível

em:

<http://www.aen.pr.gov.br/modules/noticias/article.php?storyid=94466\&amp;tit=Governo-e-Klabinfirmam-parceria-em-projeto-de-gestao-escolar>. Acesso em: 11 de março de 2018.

APP SINDICATO. Governo estadual quer entregar 31 escolas paranaenses para a Klabin. Disponível em: $<$ http://appsindicato.org.br/governo-estadual-quer-entregar-31-escolas-paranaenses-para-a-klabin/>. Acesso em: 11 de março de 2018.

TELLO, César. Apresentação. In: TELLO, César (coord. e compilador). Epistemologías de la política educativa: posicionamentos, perspectivas y enfoques. Campinas: Mercado de Letras, 2013, pp.11-20.

TEODORO, António. A educação em tempos de globalização neoliberal: os novos modos de regulação das políticas educacionais. Brasília: Liber Livro, 2011.

\section{Correspondência}

Altair Alberto Fávero: Possui Pós-Doutorado (Bolsista Capes) pela Universidad Autónoma del Estado de México (UAEMéx), Doutorado em Educação (UFRGS), Mestre em Filosofia do Conhecimento (PUC/RS), Especialista em Epistemologia das Ciências Sociais (UPF) e Graduado em Filosofia (UPF). Atua como professor e pesquisador no Curso de Filosofia, no Mestrado e Doutorado em Educação da UPF, onde coordena o Grupo de Estudos e Pesquisa em Educação Superior/GEPES/UPF.

E-mail: altairfavero@gmail.com

Carina Tonieto: É Doutora em Educação (UPF), Mestre em Educação (UPF/Bolsista Capes), especialista em Gestão Educacional (UFSM), graduada em Filosofia (UPF). Professora no Instituto de Educação, Ciência e Tecnologia do Rio Grande do Sul/IFRS/Campus de Ibirubá, vice-coordenadora do Grupo de Estudos e Pesquisa em Educação Superior/GEPES/UPF e líder do Grupo de Pesquisa Ensino, Trabalho e Sociedade/IFRS.

E-mail: tonieto.carina@gmail.com

Evandro Consaltér: É Doutorando em Educação, Mestre em Educação pela Universidade de Passo Fundo (UPF). Licenciado em Letras pela UPF. Especialista em Estratégias de Aprendizagem pela Faculdade da Associação Brasiliense de Educação (FABE). Professor do Curso de Pedagogia da FABE na cidade de Marau/RS. Integrante do Grupo de Estudos e Pesquisa em Educação Superior/GEPES/UPF.

E-mail: evandroconsalter@gmail.com 
Texto publicado em Currículo sem Fronteiras com autorização dos autores 